\title{
VIVER, MORAR, TRABALHAR: PRÁTICAS SOCIAIS E ETNICIDADE ENTRE JOVENS MAYAS EM MÉRIDA, MÉXICO
}

\author{
MARCOS H. B. FERREIRA ${ }^{1}$
}

\begin{abstract}
RESUMO
As áreas onde residem os mayas, nas periferias de Mérida, no estado mexicano de Yucatán, são representadas pelos outros habitantes da cidade como regiões precárias, violentas e perigosas. Essa representação, por sua vez, está em contradição com a percepção dos próprios moradores dessas áreas e se entrelaça com uma discriminação étnica profunda que marca a história de Mérida, desde sua fundação. Tal discriminação se traduz em uma série de estigmas a respeito dos mayas e suas práticas sociais. Nesta ocasião, seleciono algumas histórias de vida que expressam um pouco das experiências de jovens mayas residentes em Mérida e suas práticas cotidianas de morar, trabalhar e mover-se na cidade. A partir dessas histórias de vida, penso a produção das fronteiras urbanas e os processos de exclusão vividos em um contexto urbano com acentuada presença indígena, como é o caso de Mérida.
\end{abstract}

\section{PALAVRAS-CHAVE}

Práticas sociais; Jovens mayas; Etnicidades em contexto urbano.

\section{RESIDE, WORK AND BEING ALIVE: SOCIAL PRACTICES AND ETHNICITY AMONG YOUNG MAYANS IN MÉRIDA, MEXICO}

\begin{abstract}
The areas where the Mayans live, on the peripheries of Mérida, in the Mexican state of Yucatán, are represented by the other inhabitants of the city as precarious, violent and dangerous regions. This representation, in turn, is in contradiction with the perception of the residents of these areas and is interlaced with a profound ethnic discrimination that has marked the history of Mérida since its foundation. Such discrimination translates into a series of stigmas about the Mayans and their social practices. On this occasion, I've selected some life stories that express some of the experiences of young Mayans residing in Mérida and their daily practices of living, working and moving around the city. Based on these life stories, I think about the production of urban borders and the processes of exclusion experienced in an urban context with a strong indigenous presence, as is the case in Mérida.
\end{abstract}

\section{KEYWORDS}

Social practices; Young Mayas; Ethnicities in an urban context.

\section{VIVRE, TRAVAILLER ET «ÊTRE EN VIEN: PRATIQUES SOCIALES ET ETHNICITÉ CHEZ LES JEUNES MAYAS DE MÉRIDA, MEXIQUE}

\section{RÉSUMÉ}

Les quartiers où vivent les Mayas, à la périphérie de Mérida, dans l'État mexicain du Yucatán, sont représentés par les autres habitants de la ville comme des régions précaires, violentes et dangereuses. Cette représentation, à son tour, est en contradiction avec la perception des habitants de ces quartiers et se confond avec une profonde discrimination ethnique qui a marqué l'histoire de Mérida depuis sa fondation. Une telle discrimination se traduit par une série de stigmates concernant les Mayas et leurs pratiques sociales. A cette occasion, j'ai sélectionné quelques histoires de vie qui expriment certaines des expériences de jeunes Mayas

${ }^{1}$ Doutor em Antropologia pelo PPGAS/UFG. Professor do IGPA/PUC Goiás. 
résidant à Mérida et leurs pratiques quotidiennes de vie, de travail et de déplacement dans la ville. À partir de ces récits de vie, je pense à la production de frontières urbaines et aux processus d'exclusion vécus dans un contexte urbain à forte présence autochtone, comme c'est le cas à Mérida.

\section{MOTS CLÉS}

Pratiques sociales; Jeune Maya; Ethnicités dans un contexte urbain.

\section{VIVIR, TRABAJAR Y ESTAR VIVO: PRÁCTICAS SOCIALES Y ETNICIDAD ENTRE JÓVENES MAYAS DE MÉRIDA, MÉXICO}

\section{RESUMEN}

Las zonas donde viven los mayas, en las afueras de Mérida, en el estado mexicano de Yucatán, están representadas por los demás habitantes de la ciudad como regiones precarias, violentas y peligrosas. Esta representación, a su vez, se contradice con la percepción de los pobladores de estas zonas y se entrelaza con una profunda discriminación étnica que ha marcado la historia de Mérida desde su fundación. Tal discriminación se traduce en una serie de estigmas sobre los mayas y sus prácticas sociales. En esta ocasión, he seleccionado algunas historias de vida que expresan algunas de las experiencias de los jóvenes mayas residentes en Mérida y sus prácticas diarias de vivir, trabajar y moverse por la ciudad. A partir de estas historias de vida, pienso en la producción de fronteras urbanas y los procesos de exclusión vividos en un contexto urbano con fuerte presencia indígena, como es el caso de Mérida.

\section{PALABRAS CLAVE}

Prácticas sociales; Jóvenes Mayas; Etnicidades en contexto urbano. 


\section{INTRODUÇÃO}

Mérida, capital do estado de Yucatán, localizada no sudeste mexicano, tem uma população total de 892.363 pessoas. No censo de 2015, quando o Instituto Nacional de Estadística y Geografía (INEGI/México) usou pela primeira vez o critério de "auto atribuição", 48,25\% da população de Mérida se autodeclarou indígena. Apesar de existirem outras etnias, por conta de processos migratórios que ocorreram em diferentes momentos da história, a população indígena de Mérida é predominantemente maya. Os mayas ocupavam toda a região da Península de Yucatán, onde se localiza Mérida, no momento que chegaram os colonizadores espanhóis.

A população de Mérida representa 42\% da população de todo o estado de Yucatán, o que nos dá uma visão sobre a importância da cidade para aquela região. Sempre foi um centro econômico da Península, por isso, constitui um dos principais destinos de imigrantes que chegam de vários pueblos² de Yucatán e de outras partes do México. Suas principais atividades são o comércio, a indústria manufatureira e o setor de serviços, segundo o INEGI (2015). É muito evidente, no cotidiano da cidade, a importância para a economia local das atividades relacionadas ao turismo e à construção civil.

Além de possuir uma divisão muito marcada de seu espaço, com limites bem definidos entre a região Sul, a região Norte e o Centro, principalmente, Mérida possui diferenças muito evidentes nas características das paisagens e das populações que habitam cada uma dessas regiões. No cerne dessas diferenças, a questão étnica aparece como um elemento estruturante, já que, a população maya de baixa renda reside em regiões específicas, principalmente ao sul de Mérida, enquanto a população branca de média e alta renda reside principalmente ao norte (REYES, 2003; ITURRIAGA, 2011). Estas posições espaciais baseadas em fatores como etnicidade e renda podem ser observadas na história da cidade desde a sua fundação. Mas existem acontecimentos históricos recentes que influenciaram deslocamentos de pessoas e produziram esse quadro de concentração da população maya em regiões periféricas, às margens da cidade. Ou que produziram conflitos entre a população branca de alta renda e as populações mayas que habitam pueblos situados no entorno de Mérida.

Entre janeiro de 2018 e fevereiro de 2019, como estudante de doutorado em antropologia do PPGAS/UFG, realizei um intercâmbio de pesquisa no CIESAS (Centro de Investigación y Estudios Superiores em Antropología Social), México. E realizei uma etnografia sobre segregação espacial de populações mayas residentes em Mérida, Yuctán.

\footnotetext{
2 Um pueblo, no México, é uma espécie de povoado, uma pequena cidade ou localidade comumente relacionada mais ao universo rural que ao universo urbano.
} 
Fiz uma série de entrevistas sobre histórias de vida, com ênfase em atividades de trabalho e moradia. Tentei compreender, a partir dessas histórias, alguns processos de transformação no espaço urbano de Mérida, tal como foram experienciados pelas populações mayas residentes na cidade. E tentei identificar os fenómenos de segregação espacial enfrentados por estas populações ao longo desses processos (FERREIRA, 2020).

Eu me baseei na noção de "taskscape", de Tim Ingold (2000; 2015), que trata as paisagens como processos, com ênfase nas práticas sociais que as produzem cotidianamente; e na noção de "circuito", de Magnani, que designa "um uso do espaço e dos equipamentos urbanos que possibilita o exercício da sociabilidade por meio de encontros, comunicação, manejo de códigos, porém (...) sem se ater à contiguidade" (MAGNANI; ANDRADE, 2013, p. 48).

Nas próximas linhas, apresento partes de algumas dessas histórias de vida, de jovens mayas especificamente, selecionadas para esta ocasião. Em seguida, tentarei compreender o que elas são capazes de informar acerca das experiências sociais recorrentes nas trajetórias de vida de jovens mayas em Mérida. E o que essas experiências revelam sobre as relações desses jovens com a dinâmica da cidade.

\section{SKIMO}

Skimo é um dos principais artistas urbanos de Mérida. Graffiteiro, um dos pioneiros dos stickers ${ }^{3}$ e autor da personagem La Mestiza4, que por um tempo esteve muito presente nos muros da cidade, por isso é bastante conhecida, e ainda pode ser vista em alguns lugares, às vezes acompanhada da expressão em maya "Ko'ox mamii!" ("vamos, vovó!").

Skimo contou que sua família foi uma das primeiras residentes no bairro chamado Emiliano Zapata. Seu avô paterno era ejidatário ${ }^{5}$ e vendia, junto com sua avó, verduras e comida em Mérida. Seus tios venderam água por um tempo no Cementerio General, enquanto sua avó materna tinha uma banca de roupas no mercado. Hoje, os homens de sua família trabalham na construção civil. Ao longo dos anos, portanto, sua família esteve

\footnotetext{
${ }^{3}$ Os stickers, ou adesivos, são uma das modalidades de intervenção visual urbana ao lado do graffiti, do stencil, por exemplo. Os stickers são uma modalidade mais rápida de intervenção, e normalmente são aplicados (executados) em equipamentos urbanos presentes nos percursos espaciais habituais de quem executa a intervenção (FERREIRA, 2009).

${ }^{4}$ O termo mestizo/a é utilizado para se referir aos mayas na Península de Yucatán. Tenta-se por meio dele encobrir sua identidade indígena, diluí-la ou enfraquecê-la, ao misturá-la com outras identidades, mesmo que nunca se tenha conseguido realizá-lo de fato.

${ }^{5}$ No México, ejido é a categoria jurídica que designa a propriedade rural de uso coletivo cuja posse foi conquistada por meio da reforma agrária. Embora grande parte dos ejidatarios tenha ascendência indígena, e muitos se identifiquem como indígenas, o ejido não necessariamente é reconhecido oficialmente como terra indígena ou território étnico.
} 
ocupada sobretudo em atividades de trabalho relacionadas à dinâmica econômica urbana, primeiro no comércio e depois na construção civil.

As histórias de sua família se misturam com histórias de trabalho e vida laboral. Embora isso não seja exclusivo da família de Skimo, é algo muito marcante em sua fala. Suas lembranças são atravessadas pela memória de uma "vida dura", de muito trabalho, conjugada com memórias felizes nas ruas do bairro e do próprio clima de alegria no ambiente de trabalho, marcado pelo prazer de estar junto a seus familiares, e de sorrirem juntos, em meio a piadas e brincadeiras, apesar do trabalho duro na construção civil.

Figura 1. Graffitida Mestiza, personagem criada por Skimo.

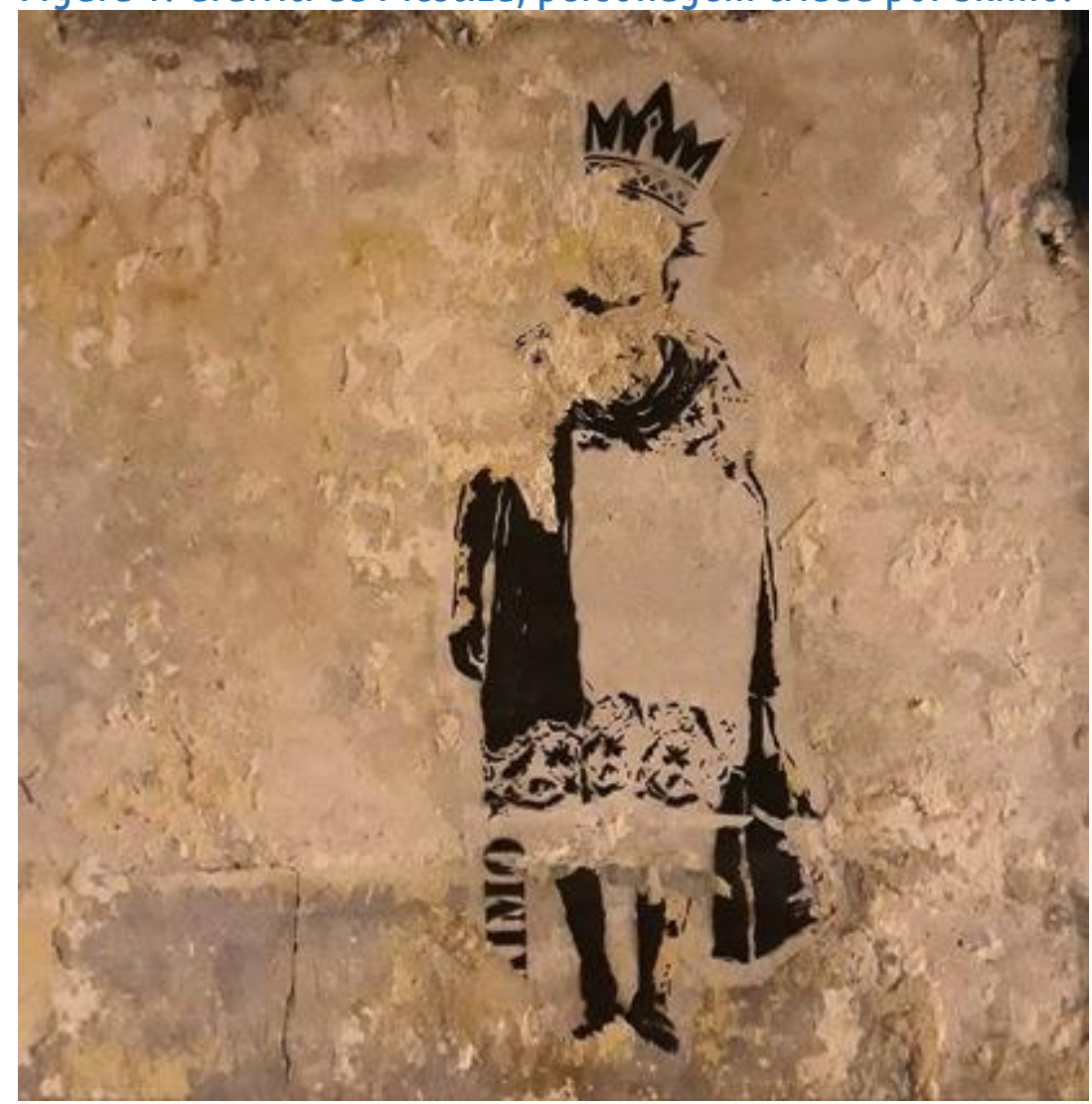

Foto: Marcos Ferreira.

Skimo concluiu o que equivaleria, no Brasil, ao ensino médio. Fez alguns cursos técnicos profissionalizantes, mas acabou não trabalhando nas áreas desses cursos porque começou a trabalhar com seu pai e seus irmãos na construção civil. Segundo ele, havia oportunidades reais de trabalho nessa área, e assim pôde ter uma renda que o sustentasse mais rapidamente.

O pai de Skimo morou de aluguel em vários bairros de Mérida antes de se mudar definitivamente para o bairro Emiliano Zapata, onde finalmente conseguiu construir, em etapas, sua própria casa. 
Skimo acompanhou uma transformação intensa na paisagem da região do bairro, simultânea ao processo de povoamento e urbanização. Suas lembranças caminham das descrições de paisagens típicas de um ambiente rural para as descrições do ambiente urbano que existe hoje, passando por um estágio de precariedade e escassez de infraestrutura, principalmente hídrica. Ele lembra que o clima era agradável antigamente, não havia asfalto, havia casas de cartón ${ }^{6}$ e de palha. Para ele, as casas com teto de palha estavam relacionadas à precariedade daquele período. Por isso foram sendo substituídas por casas de alvenaria, à medida que os moradores conseguiam ascender socialmente por meio do trabalho.

O tema "violência" aparece em sua fala como um estigma atribuído desde fora, como um preconceito, por parte dos não-moradores, em relação ao bairro. Existe em Mérida um medo da região sul que é compartilhado não apenas pelos ricos que vivem no Norte, mas também pelos amigos de Skimo que vivem em outras regiões e vão visitá-lo.

Segundo as suas memórias, algumas práticas de violência aconteciam no seu bairro na época em que existiram as pandillas ${ }^{7}$, em Mérida. Mas são lembradas por ele sempre como coisa do passado, um fenômeno circunscrito no tempo, com início e fim. Esse passado violento é tido também por Skimo como "coisa de jovens" e por isso mesmo passageira. Além dos pequenos delitos, como assaltos e tráfico de drogas em pequenas quantidades, havia um certo sentido muito incipiente de território, porque as pandillas envolviam os jovens do bairro que trocavam provocações e ameaças, relacionadas a poder passar ou não em uma determinada rua, por exemplo. O risco de violência reforçava a importância de se possuir redes sociais, pertencer a uma pandilla ou conhecer pessoas que cuidarão da sua proteção.

A família de Skimo é bilíngue. Mesmo sendo uma família urbana, todos falam maya em diferentes níveis, e a língua maya está intrinsecamente presente em seu cotidiano, inclusive nas brincadeiras e provocações feitas entre eles ou com amigos. Por falar maya, Skimo sofreu discriminação exatamente no ambiente escolar, e logo por parte da professora, que o chamou de pata rajada ("pés rachados") quando o ouviu falar em maya em determinada ocasião. A discriminação remetia à ideia de "morar em um pueblo", já que pata rajada é sinônimo de alguém que vive no campo, que trabalha na terra, que não é urbano.

Tanto na escola quanto nas ruas de sua colonia, as bromas (piadas, provocações) que faziam referência à identidade maya de forma discriminatória e inferiorizante eram muito frequentes. A influência que essas bromas exercem sobre os jovens e adolescentes de

\footnotetext{
${ }^{6}$ As telhas de cartón, feitas de material reciclável, são mais baratas, leves e práticas na instalação, mas apresentam durabilidade muito curta e são pouco seguras em relação a chuvas e furacões.

${ }^{7}$ As pandillas, no México, guardadas as diferenças, são um fenômeno parecido ao das "gangues", nos Estados Unidos, ou "galeras" (VIANNA, 1997), no Brasil. Cada um dos termos possui especificidades contextuais, mas todos se referem a fenômenos de sociabilidade entre jovens, redes de relações sociais e processos de identificação que podem ou não fazer referências à noção de território.
} 
famílias mayas é notavelmente forte, como se percebe também pelos depoimentos de Skimo.

O graffiti, em sua vida, tem relação com uma busca por suas referências identitárias, um exercício de pensar sobre si mesmo, suas origens e seu lugar no mundo. O período em que morou em Playa del Carmen, uma das cidades mais turísticas da região da Península de Yucatán, para trabalhar foi uma época um tanto nostálgica para ele e também de muitas transformações pessoais, principalmente no que diz respeito à maneira como lida com sua identidade. Em Playa del Carmen, ele teve contato mais intenso com o graffiti, e ao voltar a Mérida, desenvolveu a personagem La Mestiza, que é sua principal marca como graffiteiro:

- El personaje que haces, la mestiza, ¿de dónde viene?

- Al principio fue mi identidad, decir quién soy, de dónde vengo, porque de ahí, esas fueron mis preguntas hacia mi, [...] yo mismo me dije "¿quién soy?, ¿de dónde soy?, ¿de dónde vengo?, ¿quién está a mi alrededor?", decir esas preguntas a uno mismo te ayuda bastante. $[\ldots]$

Así surgió, decir soy de acá, soy yucateco, soy de acá, las mestizas, los niños, la gente, soy de este barrio, he visto la pobreza, he visto la riqueza, he visto todo... (Skimo [julho de 2018]. Entrevista, Mérida).

Nos nossos primeiros encontros, Skimo visivelmente não se sentia à vontade para verbalizar a respeito de suas origens e sua identidade maya. Foi quando falou da importância desse assunto em sua produção como graffiteiro que ele conseguiu verbalizá-lo, já que, para ele, seus trabalhos são uma espécie de ocupação maya do espaço público, mostrando que ele está ali presente, como parte da história dos mayas de Yucatán.

\section{GERARDO}

Gerardo Ek é um jovem advogado de origem maya, muito comunicativo e guitarrista de uma banda de ska punk em Mérida. Ele nasceu em Kimbilá, um pueblo de Yucatán onde viveu toda sua infância. Seu pai aprendeu a falar espanhol quando era já adolescente e, apesar de a língua maya ser sua primeira língua, nunca quis ensiná-la aos filhos.

Pelo fato de não falarem maya, Gerardo e seus irmãos eram considerados "menos mayas" que seus vizinhos do pueblo. Isso ele percebia tanto nas falas de seus vizinhos quanto nas relações da família dele com o Estado. Já que não participavam de alguns programas de assistência para distribuição de cestas básicas, por exemplo, até porque, muitas vezes, seu pai mesmo se recusava a participar.

Ainda assim, na escola onde Gerardo estudava, em Izamal, a cidade mais próxima do pueblo, as crianças the dirigiam bromas porque seu cabelo era arrepiado e, ao invés de chamálo pelo nome, quase sempre o chamavam de Kimbilá, nome do pueblo em que nasceu.

Além das piadas que seus colegas faziam, ir ao banheiro na escola ou na casa de um amigo da cidade era uma experiência estranha, já que em sua casa a família fazia as necessidades fisiológicas no quintal. 
Seu pai aprendeu a falar bem o espanhol e conseguiu um bom emprego em uma fábrica processadora de henequém ${ }^{8}$ que funcionava em Kimbilá. Também chegou a ocupar um posto importante no sindicato dos trabalhadores das fábricas. Com a crise final da economia de henequém, na década de 1990, a fábrica fechou, e ele foi demitido. Parte do dinheiro que recebeu como acerto, seu pai usou para reformar a casa em que viviam (trocando as telhas de cartón por teto de cimento). Nessa época, seu pai ia a Mérida todos os dias para trabalhar. Percorria de ônibus, ao todo, $140 \mathrm{~km}$ diariamente. Trabalhou em diferentes empregos, chegando a ter uma pequena loja de variedades, alugada. Por fim, fixou-se como faxineiro em uma empresa prestadora de serviços.

Um dia, seu pai e sua mãe decidiram se mudar para Mérida, deixando os três filhos no pueblo aos cuidados das tias, até que ficassem melhor instalados e toda a família pudesse migrar para a capital. Nessa época, seus pais viviam na Colonia Emilio Porteziu, em uma casa muito simples, emprestada por uma vizinha do pueblo. Gerardo lembra que, nessa época, as colonias mais precárias e segregadas de Mérida, onde se concentravam os migrantes vindos dos pueblos, eram chamadas de colonias maladrinas, ou seja, de gente "malandra", de "baixa estirpe".

Quando seu pai e sua mãe decidiram levar os três filhos para Mérida, a família foi morar na Colonia Nueva Chichén Itzá, na zona "oriente", onde já se encontravam vários outros migrantes como eles, recém-chegados dos pueblos de Yucatán. Logo que chegaram à cidade grande, Gerardo foi convidado a trabalhar em um depósito de refrigerantes. Depois de pouco tempo, foi trabalhar em uma reformadora de portas de ferro. Ele chegou a ingressar num curso técnico de turismo, mas não gostou. Foi quando iniciou o curso de direito em uma universidade sindical, cujos preços eram mais acessíveis.

Na época em que estava na universidade, Gerardo morou com sua irmã no centro de Mérida, e lembra que nesse período seu estilo de vida se transformou mais radicalmente, familiarizando-se com a intensidade do cotidiano num centro urbano. Foi também quando começou a namorar com a garota que hoje é sua esposa, e logo decidiram morar juntos. Atualmente, vivem em Ciudad Caucel, com o filho; enquanto o pai de Gerardo continua vivendo na Colonia Nueva Chichén Itzá.

Depois do nascimento de seu filho, Gerardo passou a pensar mais em sua história de vida e em seu passado no pueblo, ao ver que o filho percorre, com semelhanças e diferenças,

\footnotetext{
${ }^{8}$ O henequém (Agave fourcroydes) é uma planta nativa do Sul do México e Guatemala, que foi muito utilizada até meados do século XX para a extração de uma fibra natural que era usada principalmente na navegação. O cultivo, processamento e comercialização da fibra constituiu por muito tempo o cerne da economia da Península de Yucatán. E proporcionou, às elites locais, um grande poder econômico, que aumentou ainda mais o abismo social existente em relação aos mayas. Que por sua vez, constituíam a mão de obra extremamente explorada que sustentava toda a economia do henequém.
} 
as mesmas etapas de vida que ele percorreu. Disse que gostaria que seu filho conhecesse "suas raízes" no pueblo, mas é como se esse passado não existisse mais. Nesse momento, por um instante, seus olhos se encheram de lágrimas.

A mudança de Gerardo para Mérida significou também uma mudança muito profunda em seu modo de ser, pois teve que transformar sua maneira de falar, seu cabelo, sua linguagem corporal, enfim, sua própria forma de estar no mundo. Tal sensação de ruptura causada por esse evento em sua vida, representando um grande divisor de águas, foi algo que me impressionou em sua fala, ao longo das entrevistas.

Quando a família de Gerardo chegou a Mérida, todos falavam um espanhol "bastante carregado" e tiveram que aprender a falar um outro tipo de espanhol, da cidade. Apesar das diferenças em relação a seus vizinhos do pueblo, quando chegou a Mérida, Gerardo percebeu que era alguém que "veio de um pueblo", como qualquer um deles. Mas essa marca distintiva já estava presente desde a época em que estudava no município de Izamal.

Gerardo concluiu os estudos universitários em Mérida, obtendo sucesso profissional e certo êxito econômico. Hoje seu pai já está aposentado, e Gerardo o ajuda financeiramente. Certas atividades se configuram como típicas dos mayas em Mérida - por sinal, desvalorizadas, mal remuneradas e marcadas pela informalidade, precariedade e exploração. Muitos homens mayas trabalham na construção civil. Nessa área, frequentemente são classificados pelos não-mayas, de forma preconceituosa, como "indisciplinados", pois supostamente bebem no trabalho, não cumprem o combinado e realizam "trabalhos malfeitos", toscos ou descuidados. Mas seguem sendo muito contratados, talvez porque aceitem as menores remunerações. Gerardo rompe com esse estereótipo, pois trabalha como advogado em um órgão federal.

Ainda assim, ele sofre preconceito em Mérida, não mais por suas práticas sociais, aquilo que Pierre Bourdieu (2002) chama de habitus, mas por seu sobrenome maya. Muitas vezes, quando solicita um serviço - a instalação de um aparelho de ar-condicionado, por exemplo - não é atendido. Quando cobra o serviço da empresa que havia contatado, percebe que não deram importância ao seu pedido por conta de seu sobrenome maya, por desconfiarem que ele não teria condições de pagar pelo serviço e que não seria de fato um "cliente em potencial".

Gerardo fala sobre suas origens mayas com um discurso politicamente engajado; contudo, essa autoidentificação está colada a um discurso de superação e êxito pessoal, já que ele estudou e hoje é advogado. Também representa um exemplo interessante de mayas que tiveram sucesso profissional em Mérida, ascenderam socialmente, precisaram mudar comportamentos, ou habitus, mas continuam sofrendo discriminações no cotidiano, mesmo 
que de forma velada, por conta do sobrenome ou qualquer outro marcador social de diferença.

\section{Figura 2. Gerardo.}

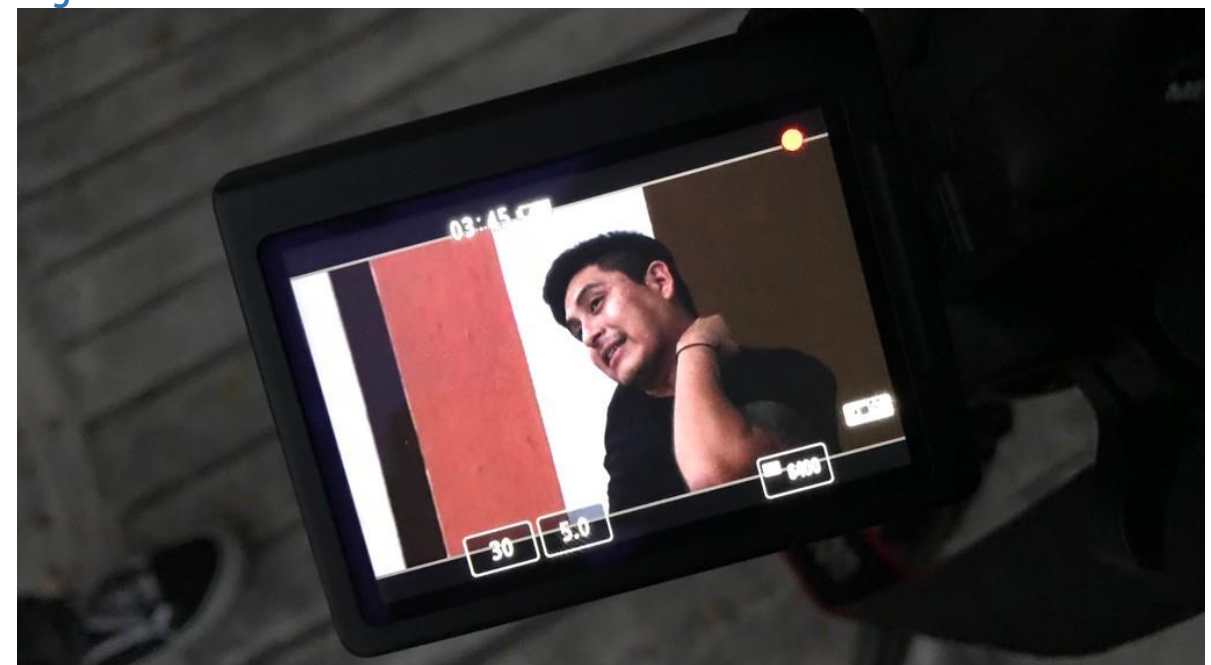

Foto: Sofia Castillo.

\section{RICHO}

Richo é um jovem artista plástico bastante conhecido em Mérida e músico percussionista de cúmbia. Tem se despontando no circuito das artes plásticas de Mérida, participando de algumas exposições e comercializando bem suas obras. Nasceu no mesmo pueblo que Gerardo, Kimbila, embora não sejam amigos próximos, apesar de se conhecerem. Richo é bem mais jovem que Gerardo; mudou-se para Mérida nos anos 2010, para estudar Artes Visuais na UADY (Universidad Autónoma de Yucatán). Trabalhou por um tempo como músico de rua, até iniciar seu trabalho como artista visual. Hoje continua tocando em uma banda de cúmbia, em bares e restaurantes de Mérida.

As memórias que ele tem do pueblo influenciam muito seu trabalho como artista. Nestas memórias, as relações entre o espaço da cidade e o espaço do pueblo acabam apontando para a existência de outras duas dimensões ou espacialidades: o rancho, e, junto com ele, a selva. São fortes em sua fala as referências às experiências vividas no rancho de seu avô, que era uma espécie de "segunda casa" para sua família, e estava há alguns quilômetros do pueblo, em uma área de mata densa. O rancho aparece como uma dimensão do mundo rural existente para além do pueblo, marcada pela presença de plantações e animais domésticos. Da mesma maneira, para além do rancho, existe ainda a selva, a mata fechada, não dominada pelo humano, com seus sons, plantas, cores e animais não domésticos.

As plantas e suas cores aparecem também nos bordados aos quais se dedicam sua mãe, suas tias e boa parte da população do pueblo. Sua família possui uma tradição de 
atividades laborais artísticas que chega até ele e a irmã, que atualmente também estuda artes visuais. O universo de cores, técnicas e materiais existente em torno da atividade dos bordados é parte importante do referencial de experiências vividas por ele no pueblo.

Junto a isso está a música, o violão que seu avô tocava, a cúmbia que se escutava no pueblo, e os rituais realizados em torno da milpa ou no dia de finados. Os animais da selva, o veado e o jaguar (onça, Panthera onca), principalmente, estão presentes nas histórias e cosmologia dos antigos mayas. Richo demonstra conhecê-las bem, o jaguar está presente com frequência em sua produção como artista plástico, além da morte como tema, relacionada a deuses, símbolos e situações rituais.

Mudar-se para Mérida com o propósito de estudar e trabalhar foi um processo difícil para ele, devido ao choque cultural produzido pelo encontro com a intensidade da experiência urbana de viver na capital. Perdia-se no centro ao descer de um ônibus, ficava nervoso e quase chorava, imaginando o que poderia acontecer com ele ali. Foi um processo um tanto solitário, já que ele foi o primeiro da sua família a migrar, muito jovem, a Mérida.

O que permitiu a Richo realizar essa passagem, do pueblo à cidade, como espaço de moradia, foi o fato de ter começado a tocar com amigos nas ruas de Mérida, em troca de gorjetas. Essa fonte de renda foi o que garantiu autonomia financeira naquele momento.

Falar bem a língua maya abriu várias portas para Richo, do ponto de vista profissional, no mercado das artes. E segue abrindo, já que os comentários sobre seu trabalho nas artes plásticas remetem, muito frequentemente, à sua identidade maya. Isso foi uma surpresa para o próprio Richo, que esperava que o fato de falar maya seria fonte de preconceitos, mais do que de oportunidades profissionais.

Ele também é um exemplo de jovens mayas que, tendo concluído um curso superior, possui uma visão crítica e bem-informada sobre o que é ser maya. Se considera parte de um grupo de "novos mayas", os "mayas de hoje", que conhece e valoriza a história dos mayas da Península, ao mesmo tempo em que chama atenção para as novas maneiras de se relacionar com essa história e os novos processos de identificação:

Fíjate que interesante... yo nazco en el 90, han pasado muchos años desde que la civilización maya cayó en la colonia, desde que la rebelión, la guerra de castas, han pasado muchas cosas y yo nazco en esta época, donde yo puedo ir a la red y descargar toda la información, y a través de esa información sentirme todavía más atraído, porque la historia también es importante... desde esa retroalimentación de información, yo empiezo a relacionarlo con mi vida cotidiana, y digo: "oh sí y, me siento orgulloso y digo soy maya". Pues, yo te digo, yo me identifico como maya, maya contemporáneo, maya actual, [...] me gusta pensar en eso... si yo nací en una comunidad donde la mayoría de la gente habla maya, yo hablo maya, donde, durante mi infancia yo iba a la milpa con mi abuelo a sembrar, a cosechar, formé parte de los rituales, yo vi los rituales que se hacen... (Richo [outubro de 2018]. Entrevista, Mérida).

\footnotetext{
${ }^{9}$ Milpa é o nome que os mayas de Yucatán utilizam para se referirem à plantação (ou "roça"), de milho e também de outras espécies.
} 
Flores, cores, animais da selva e a morte como temas são a marca mais destacada de sua produção como artista. De maneira inusitada, essas referências serviram como um capital simbólico que tem lhe garantido certo êxito no mercado de trabalho das artes visuais.

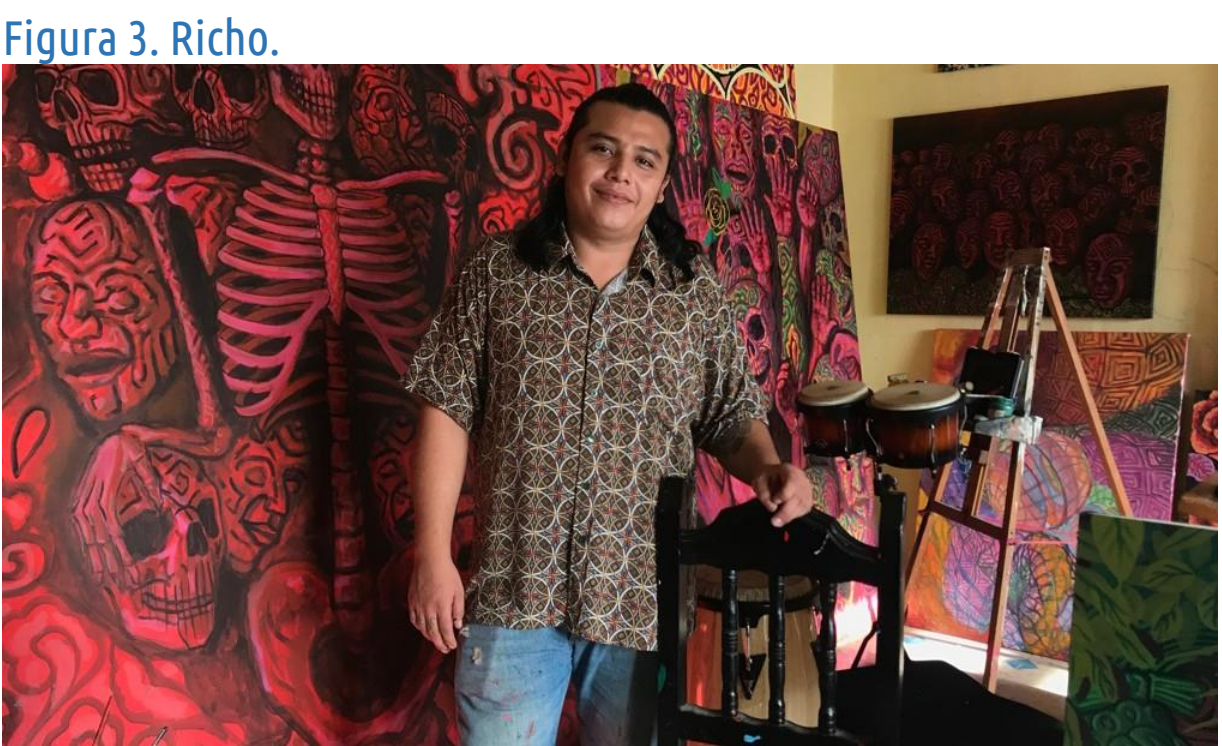

Foto: Sofía Castillo.

\section{"ESTAR VIVO": MORAR, TRABALHAR, MOVER-SE PELA CIDADE}

Em práticas de trabalho, tão diversas quanto construção civil, comércio de verduras no centro, atendimento ao turismo e mercado das artes, as referências aos mayas de Yucatán podem produzir êxito e valorização profissional, mas também racismo e precarização. Quando a identidade maya está amarrada à categoria mestizo, quase simultaneamente está também vinculada à ideia de pobreza, marginalidade e vida nos pueblos. Quando se remete à história dos mayas pré-hispânicos, com frequência é motivo de orgulho, relacionado à ideia de riqueza cultural, exotismo e "esplendor".

Nas histórias que reuni acima, os aspectos sobre moradia e sobre trabalho foram capazes de mobilizar memórias muito diversas e organizar narrativas significativas sobre as experiências dos mayas em Mérida atualmente. As atividades de trabalho são um caminho pelo qual os mayas se inserem nos espaços e no cotidiano da cidade. A migração de um pueblo à cidade, para estudar ou trabalhar, é sempre uma experiência marcante no que se refere à maneira como a identidade indígena e as formas de racismo são vivenciadas. Nas histórias de moradia, são comuns as inúmeras mudanças de local de residência, repetindo um padrão de deslocamento que vai dos bairros mais centrais em direção às periferias da cidade.

Segundo David Harvey:

\footnotetext{
"As biografias individuais podem ser tomadas como "trilhas de vida no tempo-espaço", começando com rotinas cotidianas de movimento (da casa para a fábrica, as lojas, a escola, e de volta para a casa) e estendendo-se a movimentos migratórios que alcançam a duração de uma vida (por exemplo, juventude no campo, treinamento profissional na cidade grande, casamento e mudança para os subúrbios, e aposentadoria passada no campo)" (HARVEY, 2011, p. 195).
} 
Tim Ingold, por outro lado, partindo da premissa de que "vida é movimento", argumenta que a noção de espaço com a qual estamos acostumados dentro da tradição ocidental resulta do que ele chama de "lógica da inversão"; que transforma "as vias ao longo das quais a vida é vivida em limites dentro dos quais está encerrada" (INGOLD, 2015, p. 215).

Nesse sentido, para Ingold (2015), a noção de espaço tende a delimitar a vida que, por estar em movimento, extrapola qualquer tentativa de delimitação. Ao contrário disso, para o autor, os lugares são como elos entre linhas que formam uma grande rede de movimentos. Uma casa, por exemplo, é um "lugar onde as linhas de seus residentes estão fortemente atadas". Mas a casa não contém e nem pode conter estas linhas. Elas continuam "para além" da casa, até encontrarem-se com outras linhas, produzindo outros nós, e assim por diante:

"Os lugares, em suma, são delineados pelo movimento, e não pelos limites exteriores ao movimento. (...) enquanto a ocupação é de uma área, a habitação é linear. Ou seja, leva as pessoas não através da superfície da Terra, mas ao longo dos caminhos que levam de um lugar ao outro. Da perspectiva dos habitantes, portanto, "em todos os lugares" não é espaço. É toda a malha de trilhas interligadas ao longo das quais as pessoas vivem suas vidas. Enquanto está na trilha, uma pessoa está sempre em algum lugar. Mas todo "em algum lugar" está no caminho para algum outro lugar (INGOLD, 2007a: 81). Este é um momento apropriado, portanto, de passar do lugar ao movimento. Como é que nossa compreensão do movimento foi transformada pela lógica da inversão?" (INGOLD, 2015, p. 220).

Apesar de provocativo e instigante, o argumento de Ingold parece supervalorizar o movimento e desconsidera os fatores que possam interferir sobre ele. Harvey já havia comentado que "Os recursos temporais finitos e a "fricção da distância" (medida em tempo e gastos necessários para vencê-la) restringem o movimento diário" (HARVEY, 2011, p.195). Também devemos lembrar que grupos de indivíduos diferentes estão relacionados a tipos diferentes de movimentos que podem ser voluntários ou forçados:

"É preciso encontrar tempo para comer, dormir etc., e os projetos sociais sempre encontram "restrições de contato", especificadas como a necessidade de intersecção das trilhas de tempo-espaço de dois ou mais indivíduos para que qualquer transação social seja realizada. Essas transações ocorrem tipicamente no âmbito de um padrão geográfico de "estações" disponíveis (lugares onde certas atividades, como trabalhar, fazer compras etc., ocorrem) e "domínios" em que certas interações sociais prevalecem" (HARVEY, 2011, p. 195).

Mas Ingold talvez não discordaria dessa posição; e aqui encontramos o ponto comum entre ele e Harvey, a saber, o fato de que ambos resolvem seus próprios empasses acerca da experiência espacial (ou, como Ingold prefere dizer, a experiência através dos lugares) recorrendo-se ao conceito de habitus, de Bourdieu (2002). Visto que, se essa experiência de movimento é uma experiência corporal, a de se considerar que o corpo é, por sua vez, a dimensão mais social da experiência espacial. Isso porque, conforme já havia concluído Bourdieu: 


\begin{abstract}
"As ordenações simbólicas do espaço e do tempo fornecem uma estrutura para a experiência mediante a qual aprendemos quem ou o que somos na sociedade. "A razão pela qual a submissão aos ritmos coletivos é exigida com tanto rigor" (...) "é o fato de as formas temporais ou estruturas espaciais estruturarem não somente a representação do mundo do grupo, mas o próprio grupo, que organiza a si mesmo de acordo com essa representação." (...) é através "da relação dialética entre o corpo e uma organização estruturada do espaço e do tempo que as práticas e representações comuns são determinadas". E é exatamente a partir dessas experiências (na casa em particular) que se impõem esquemas duradouros de percepção, de pensamento e de ação" (BOURDIEU, 1977, p. 163 apud HARVEY, 2011, p.198).
\end{abstract}

Em outras palavras, Bourdieu (2002) nos ajuda a compreender de que maneira as posições sociais e de classe se expressam também na forma de posições espaciais, bem como nos encontros (ou ausência de encontros) que acontecem na cidade. Inscrito nas práticas sociais, o habitus fornece conteúdo para os encontros sociais que atravessam o cotidiano da cidade. Ao mesmo tempo, o habitus organiza essas práticas, fornecendo-lhes uma estrutura, uma ordem, que, por sua vez, expressa as desigualdades de classe social. Desta maneira, segundo Bourdieu, o habitus serve para "manter as distâncias" e lembrar aos indivíduos de suas posições (BOURDIEU, 2002, p. 177-178). Assim, permite que o indivíduo possa "ir", ou, por outro lado, o induz a "ficar no seu lugar".

No livro Las estructuras sociales de la economia (2008), Bourdieu atribui a mobilidade e a não mobilidade residencial de ricos e pobres como dependente da posse ou não de capital econômico e cultural:

\begin{abstract}
"Desde su punto de vista, la movilidad o la fijación de los actores en el territorio, en el espacio de la ciudad, por ejemplo, es algo que no se debe al espacio mismo; no existe un arraigo o fijación de los actores que dependa estrictamente del lugar. La atadura al espacio, o las posibilidades de romper con esa atadura, está en función de la posesión o carencia del recurso económico que está en la base del orden social. El espacio urbano, que es un espacio marcado por la exclusión social, en términos de su relación con los atores sociales, se hace específico en cuanto actúa como medio, como mecanismo para que los propietarios de los recursos más significativos y los desposeídos establezcan el mapa de las diferenciaciones sociales" (LEZAMA, 2014, p. 30-31).
\end{abstract}

O ponto mais importante desta argumentação é que as práticas e experiências sociais, os encontros cotidianos e seus percursos, o próprio ato de morar e mover-se na cidade, ajudam a produzir uma realidade estruturada, visível no espaço urbano e na forma como ele se apresenta. Por isso, para Bourdieu (2002), as "estruturas objetivas" que a ciência tenta apreender por meio da estatística (com seus gráficos e tabelas), conferem, nos termos do próprio autor, "a fisiognomia" de um "meio ambiente social", uma espécie de "paisagem coletiva" com suas ruas fechadas ou seus lugares inacessíveis, por exemplo. Porém, muito mais do que isso, também inculcam através de experiências convergentes, e recorrentes, um certo sentido de realidade que seria, para Bourdieu, o princípio mais bem escondido das estruturas sociais, e o princípio de sua eficácia (BOURDIEU, 2002, p. 182-183). 
Nesse sentido, as experiências de movimento dos jovens mayas em Mérida referemse, num primeiro nível, a seus trajetos cotidianos, circuitos coletivos e encontros experimentados entre a casa e o trabalho, ou entre espaços de consumo e lazer. Portanto, o enfoque que dou às práticas de moradia e trabalho é apenas um recorte para a análise, uma seleção, já que poderiam ser realizadas outras abordagens que enfatizassem outras práticas sociais, como consumo e lazer. Todos os movimentos e deslocamentos envolvidos nessas práticas evidenciam a localização (espacial e social) de seu narrador, nos termos de seu pertencimento de classe, raça e etnia, considerando-se a ordem espacial produzida ao longo dessas experiências e a maneira como essas se articulam a questões étnicas e sociais.

Em um segundo nível, as experiências de movimento narradas referem-se às mudanças de moradia vivenciadas ao longo da história da família, desde a grande experiência de mudança cultural, a migração do pueblo à cidade, principalmente depois do colapso da economia do henequém (LIZAMA QUIJANO, 2007; 2013) até o processos espaciais de transmissão de terras entre indígenas e espanhóis nos bairros periféricos de Mérida no século XVIII (e que hoje são parte da região central) ou o atual trânsito cotidiano de trabalhadores entre os pueblos e Mérida (BRACAMONTE Y SOSA, 2013).

Esses movimentos informam, a partir de um plano micro, ou seja, da experiencia pessoal, um processo mais amplo de exclusão e expulsão indireta dos mayas para as regiões mais periféricas da cidade. Esse processo produziu uma distribuição espacial marcada por um "padrão de segregação" (CALDEIRA, 2011) baseando simultaneamente nas divisões entre norte e sul; centro e periferias, com os mayas residindo predominantemente nas periferias ao sul de Mérida, que é a região mais estigmatizada da cidade, tida pelos não moradores como uma área perigosa, precária e violenta.

Alícia Castellanos Guerrero $(2001 ; 2003)$ ao pensar sobre o racismo no México, já havia chamado atenção para a influência que exercem as elites locais e as ideologias que estas produzem a respeito dos indígenas, em cada contexto regional, de acordo com os interesses em questão. O estigma construído em relação aos espaços onde residem os mayas de Mérida, faz parte da discriminação étnica profundamente enraizada na história de Yucatán. O que impõe uma situação paradoxal aos mayas de Mérida que, apesar de se reconhecerem como mayas, como indicam os dados do INEGI (2015), dificilmente podem expressar ou vivenciar sua identidade étnica livremente no espaço urbano.

Devido à ideia de que os mayas são uma cultura do passado, motivo de orgulho, ou uma cultura presente nos "pueblos", na zona rural, mas não na cidade, os mayas de Mérida vivenciam uma situação complexa, como se estivessem em uma espécie de "sem lugar" no espaço social. Muitas vezes o único lugar que lhes resta no imaginário social racista construído ao longo da história de Yucatán é o de "pobres urbanos", habitantes das periferias 
estigmatizadas da cidade, ou inseridos em trabalhos precários, desvalorizados e mal remunerados.

Esta situação está sendo rompida porque as novas gerações de mayas residentes em Mérida trazem uma série de novos discursos e ocupam novos espaços que contradizem os estereótipos existentes na ideologia hegemônica acerca dos mayas de Yucatán. Jovens artistas, músicos, professores e outros profissionais mayas, ao ressignificarem tais estereótipos, chamam atenção para a presença indígena em Mérida, que sempre existiu de maneira inconteste, mas que era invisibilizada assim por meio do preconceito e da exclusão.

\section{REFERÊNCIAS}

BOURDIEU, Pierre. Esboço de uma teoria da prática: precedido de três estudos de etnologia cabila. Tradução de Miguel Serras Pereira. Oeiras, Portugal: Celta Editora, 2002.

BRACAMONTE Y SOSA, Pedro. La península remodelada: los mayas y la movilidad espacial. In: QUIJANO, Lizama Jesús (Ed.). Entre irse y quedarse... Estructura agraria y migraciones internas en la Península de Yucatán. Editorial Letra Antigua, Mérida, 2013. p. 31-72.

CALDEIRA, Teresa. Cidade de muros. São Paulo: Editora 34, 2011.

CASTELLANOS GUERRERO, Alicia. Imágenes del racismo en México. México, UAM y Plaza y Valdés, p. 35-142, 2003.

CASTELLANOS GUERRERO, Alicia. Notas para estudiar el racismo hacia los indios de México. Papeles de población, v. 7, n. 28, p. 165-179, 2001.

CENSO, INEGI. Instituto Nacional de Geografia y Estadistica. 2015.

FERREIRA, Marcos Henrique Barbosa. Imagens da cidade: cidade imaginada: sobre graffiteiros e pixadores em Belo Horizonte. Dissertação de Mestrado em Antropologia, Universidade Federal de Minas Gerais, UFMG, Belo Horizonte, 2009.

FERREIRA, Marcos Henrique Barbosa. Etno-cidade: mayas em Mérida hoje. Tese de Doutorado em Antropologia Social, Universidade Federal de Goiás, Goiânia, 2020.

HARVEY, David. Condição pós-moderna. São Paulo: Loyola, 2011.

INGOLD, Tim. Estar vivo: ensaios sobre movimento, conhecimento e descrição. Rio de Janeiro: Vozes, 2015.

INGOLD, Tim. The Perception of the Environment: essays on livelihood, dwelling and skills. London and New York: Routledge, 2000.

INGOLD, Tim. Líneas: una breve historia. Editorial Gedisa, 2007. 
ITURRIAGA, Eugenia. Las élites de la ciudad blanca: racismo, prácticas y discriminación étnica en Mérida, Yucatán. Tesis de doctorado en el Instituto de Investigaciones Antropológicas, México: FFyLUNAM, 2011.

LEZAMA, José Luis. Teoría social, espacio y ciudad. El Colegio de México, 2014.

LIZAMA QUIJANO, Jesús (org.). Entre irse y quedarse...: estructura agraria y migraciones internas en la península de Yucatán. Mérida: Letra Antigua, 2013.

LIZAMA QUIJANO, Jesús. Estar en el mundo: procesos culturales, estrategias económicas y dinámicas identitarias entre los mayas yucatecos. CIESAS, 2007.

MAGNANI, José Guilherme Cantor; ANDRADE, José Agnello Alves Dias de. Uma experiência de etnologia urbana: a presença indígena em cidades da Amazônia. In. AMOROSO, M.; DOS SANTOS, G. M. Paisagens Ameríndias. Lugares, circuitos e modos de vida na Amazônia. São Paulo: Terceiro Nome, 2013. p. $45-74$.

REYES, Guadalupe. Carnaval en Mérida: fiesta, espectáculo y ritual. Conacultura, INAH, Colección Obra Varia, 2003.

VIANNA, Hermano. Galeras Cariocas: Territórios de Conflitos e Encontros Culturais. RJ: Ed. UFRJ, 1997.

Recebido em 01 de fevereiro de 2021. Aprovado em 27 de setembro de 2021. 